\title{
Phyto-Nutrients, Nutraceutical, Fermented Foods and Traditional Medicine in Human Health: Issues, Concerns and Strategies
}

\author{
VK Joshi* \\ Department of Forestry, YSP University of Horticulture and Forestry, India \\ *Corresponding author: VK Joshi, University of Horticulture and Forestry, Nauni, Solan, HP, India \\ Submission: December 29, 2017; Published: March 29, 2018
}

\begin{abstract}
Recently, many diseases related to the life style or the ageing have grown by leap and bounds, needing appropriate solutions and the present focus is to find solace in the lap of nature. The various approaches include the use of herbal or plant medicines (being used from an ancient time all over the world especially India, China and several other countries of Asia), health foods (functional foods), fermented foods, phyto-chemicals and nutraceuticals, bioactive compounds, etc in the cure of such diseases. The major reason for their use is the general belief amongst the people is that such substances are useful in the cure and do not cause any side effect unlike the allopathic medicines. The phyto-chemicals, nutraceuticals, bioactive compounds or the fermented foods have been claimed for the cure of several ailments. The foods containing the phyto-chemicals are termed as nutraceuticals include various nutrients, dietary supplements, specially designed diets or herbal products of both plant and animal origin. However, there are several concerns in the use of these types of approaches and the products. For example many nutraceuticals, herbal medicines or similar photo-chemicals, fermented foods have never been investigated at all for their active component, mechanism of action, metabolic pathways, therapeutic values or the demonstratable effect in model systems. So it is important to apply modern science and tools including chemo-matrix, metabolomics, nutrigenomic to understand the traditional systems of medicine (phyto-chemicals, the Traditional System of Chinese Medicine (TSCM), Ayurveda) and phyto-chemicals with advanced biotechnology, diverse applications and advantages could be exhibited not only in bringing benefits to increase the diversity and composition of herbal phyto-chemicals, but also helping to elucidate the treatment mechanism and accelerate new drug discovery from Chinese herbal medicine. The mechanism of action along with the efficacy of various phyto-chemicals in different clinical conditions needs to be established with help of in vivo studies. Indigenous fermented foods are the major sources of bioactive compounds, reflecting the great usefulness of these foods in human health. It is apparent that interdisciplinary research involving biochemistry, nutrition, microbiology, physiology, pathology and pharmacology should be conducted especially validation. Another concern for the use of nutraceuticals is the lack of quality control, a very serious aspect which needs to be tackled with suitable standards and the methods of evaluation. Overall, it is clearly a fertile ground research for the future. Abbreviations: TSCM: Traditional System of Chinese Medicine; NCDs: Non-Communicable Diseases; WHO: World Health Organization; CVD: Cardiovascular Diseases; Das: Dicarboxylic Acids; HMPs: Herbal Medicinal Products; SRs : Systemic Review; EFSA: European Food Safety Authority; TCHM: Traditional Chinese Herbal Medicine; CHM: Chinese Herbal Medicine; QAMS: Quantitative Analysis Of Multi-Components By Single Marker
\end{abstract}

\section{Introduction}

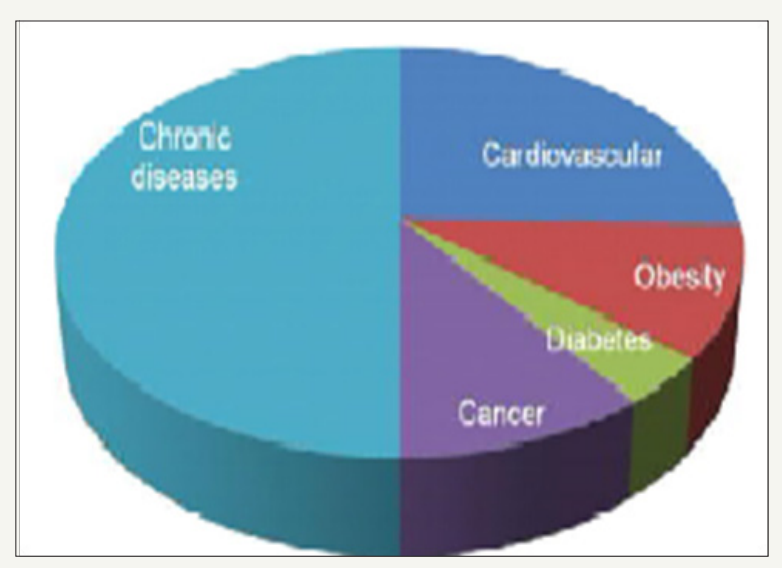

Figure 3: Global scenario of chronic diseases.
The advancement of science has enabled the man to fight the communicable diseases and the diseases caused by the micro organisms with food and water as vectors. But the diseases related to life style or the aging are growing by leap and bounds and needs appropriate solution. According to the recent World Health Organization (WHO) reports, non-communicable Diseases (NCDs) are the leading cause of mortality in the world, representing more than $60 \%$ of all the deaths out of which $30 \%$ of deaths comprised of cardiovascular diseases (CVD) followed by obesity and diabetes together Sharma 2018 (Figure 1). The net result is the focus of mankind to find solace in the lap of nature. This includes use of fermented foods, phyto-chemicals and nutrceuticals, bioactive compounds in the cure of such diseases while fermented foods and traditional medicines and/or herbal medicines are finding 
a prominent place in the traditional treatment of such diseases. The major reason for their use is the general belief amongst the people is that such substances are useful in the cure of such disease and do not cause any side effect unlike the allopathic medicines. What are these phyto-chemicals, nutraceutical or the bioactive compound or health foods or the fermented foods, how these are useful and what problems are associated with these and related aspects have been discussed in this article

\section{Health Foods}

In the traditional system of medicine, the food assumes a great significance especially the health foods. The term health food is generally used to describe foods that are considered to be beneficial to health beyond a normal diet required for human nutrition $[1,2]$. The use of foods for promoting health and relieving symptoms is as old as the practice of phyto-medicine for treating or preventing various types of illness as has been documented in Hippocratic and Vedic texts and the canons of Traditional Chinese Medicine. Thus, "Let food be the medicine and medicine be the food", quoted by Hippocrates about 2,500 years ago is certainly the tenet of today and is receiving the over-whelming response. In the recent years, rapid urbanization, industrialization, increased in per capita income etc. have changed dramatically the lifestyle of man leading to several diseases like coronary heart disease, obesity, diabetes, cancer and hypertension. The transition from a traditional to modern life style diet leads to the consumption of diets rich in fat and calories combined with a high level of mental stress have further compounded the problem. Further, food products available in the market are generally concentrated source of sugar and excess calorie intake is, therefore partially responsible for hypertension, increased incidence of diabetes mellitus and obesity, as written earlier.

To solve such problems, one of the approaches [3] is to replace the sweet taste tasting substances having high calorific values with those with lower calories non-sweeteners having sweet taste which is one of the fundamental sensations for which people strive to get. Non-nutritive sweeteners are substances which have less than 2 per cent of the calorie value of sucrose per equivalent unit of the sweetening capacity and have a sweet taste but are no-low caloric, thus, hold promise for preparation of this type of products. Some of the non-sweeteners used for the preparation health foods are listed in Table 1. Similar to this, another approach is the production of those foods having specific improvement that could be used in the cure of these life style desires. Some of the functional compounds with specific composition and sources are shown in the Table 2. Type 2-diabetes mellitus is often associated with obesity and insulin resistance. Even-number, medium-chain dicarboxylic acids (DAs), naturally occur in higher plants as components of natural protec $\neg$ tive polymers, cutin and suberin, a support biopolyester that waterproofs the leaves and fruits, regulating the flow of nutrients and minimizing the harmful impact of pathogens Kolattukudy 2001.

Table 1: Some of the non-sweetners used in the preparation of health sweetners.

\begin{tabular}{|c|c|c|c|}
\hline Sweetness & Relative Sweetness(Sucrose $=1$ ) & Kcal/g & Regulatory Status \\
\hline \multicolumn{4}{|c|}{ Less sweet than sucrose (Polyols or Novel Sugars) } \\
\hline Sorbitol & 0.6 & 2.6 & $\begin{array}{l}\text { GRAS, label must warn about its } \\
\text { laxative effect }\end{array}$ \\
\hline Mannitol & 0.7 & 1.6 & $\begin{array}{c}\text { Approved food additive, label must } \\
\text { warn about its laxative effect }\end{array}$ \\
\hline Xylitol & 0.8 & 2.4 & Approved food additive \\
\hline Isomalt & $0.45-0.55$ & 2 & GRAS, approved as bulking agent \\
\hline Sweeter than sucrose Cyclamate & 30 & 0 & GRAS, approved in many countries \\
\hline Acesulfame-K & 130 & 0 & $\begin{array}{c}\text { GRAS, approved as general purpose } \\
\text { sweetner }\end{array}$ \\
\hline Aspartame & 180 & 4.0 & $\begin{array}{c}\text { GRAS, approved as general purpose } \\
\text { sweetner }\end{array}$ \\
\hline Saccharine & $500-600$ & 0 & $\begin{array}{c}\text { Approved as a sweetner for } \\
\text { beverages and as a tabletop } \\
\text { sweetner }\end{array}$ \\
\hline Sucralose & & 0 & $\begin{array}{l}\text { Approved as general purpose } \\
\text { sweetner }\end{array}$ \\
\hline Neotam & 8000 & 0 & $\begin{array}{l}\text { Approved as general purpose } \\
\text { sweetner }\end{array}$ \\
\hline Stevioside(Stevia) & $250-300$ & 0 & $\begin{array}{c}\text { Legal in US and has received GRAS } \\
\text { approval }\end{array}$ \\
\hline
\end{tabular}


Table 2: Type of functional foods, functional properties and their source.

\begin{tabular}{|c|c|c|c|}
\hline S. No. & $\begin{array}{c}\text { Type of Functional Compound/Typical } \\
\text { Component }\end{array}$ & Functional Properties & Sources \\
\hline 1 & $\begin{array}{l}\text { Carotenoids (alpha- and beta-carotene, } \\
\text { cryptoxa-nthin,lutein,lycopene,zeaxanthin) }\end{array}$ & Quench singlet and triplet oxygen & $\begin{array}{c}\text { Red, Orange and yellow fruits and } \\
\text { vegetables }\end{array}$ \\
\hline 2 & $\begin{array}{l}\text { Glucosinolates, isothiocyanates (indole-3- } \\
\text { carbinol sulphpraphane) }\end{array}$ & $\begin{array}{l}\text { Increase Xenobiotic metabolism } \\
\text { and alter estrogen metabolism }\end{array}$ & Cruciferous vgetables \\
\hline 3 & Inositol phosphates (inositol hexaphosphate) & Stimulate natural killer cell function & Soy foods \\
\hline 4 & Isoflavones (genintestine,daidzein) & $\begin{array}{l}\text { Estrogen agonist and antagonist, } \\
\text { induceapoptosis }\end{array}$ & Soy foods \\
\hline 5 & $\begin{array}{c}\text { Phenolic acids } \\
\text { (gallic,ellagic,ferulic,chlorogenic,coumaric) }\end{array}$ & $\begin{array}{l}\text { Antioxidant,enhance xenobiotic } \\
\text { metabolism }\end{array}$ & Various fruits and vegetables \\
\hline 6 & Phytoallexins (resveratrol) & Antioxidant,platelelate inhibition & Red Wine \\
\hline 7 & $\begin{array}{l}\text { Polyphenols (flavonoids, } \\
\text { chalcones,catechins,anthocyanins) }\end{array}$ & $\begin{array}{c}\text { Antioxidant,enhance xenobiotic } \\
\text { meta bolism,nhibit numerous } \\
\text { enzymes }\end{array}$ & $\begin{array}{l}\text { Various fruits and vegetables, Red } \\
\text { wine and tea }\end{array}$ \\
\hline 8 & Sulfides (diallyl sulfides) & Antimicrobial, antioxidant & Onions and garlic \\
\hline
\end{tabular}

These acids are a promising alternative as energy substrate. Use of dicarboxylic acids has been proposed in diabetes as proved in animals and humans with two type diabetes and oral administration of sebacic acid improved glycaemic control, probably by enhancing insulin sensitivity and reducing hepatic gluconeogenesis and glucose output [4]. Since, the end product of Beta-oxidation is succinic acid which enters the TCA as reviewed earlier [4]. More studies are needed to elucidate the fate of DAs in different tissues and organs in diabetes, as well as the potential for use of these Di-acids in eternal nutrition and as a natural food ingredient in patients with type 2-diabetes in daily life and during physical exercise.

\section{Fermented Foods}

Different fermented foods including alcoholic beverages have been an indispensable part of diet of man all-over the world [5-8]. Fermented foods are the results of the activity of microorganisms or their enzymes and various fermented products are made depending upon these types of fermentation involved in the production of fermented food. Since the fermented foods constitute an integral part of human diet, appraisal of their nutritional contribution is essential especially the presence of nutrients in the original raw material and fermented products. Presence of any toxic compound in fermented products and their significance is of utmost importance from safety point of view $[9,10]$. The fermented foods are actually more nutritious than their unfermented counter-parts which can come about in many different ways such as summarized in Table 3. Amongst the fermented products, wine has been consumed throughout the ages as a food and food adjunct and there is no doubt that the wine is a healthful beverage [11]. The virtues of wine have been exploited in folklore and in medical arts and sciences though the experimental evidence in its favor came only recently. Healthful aspects of wine have been reviewed excellently earlier [12]. The effects of consumption of wine on the consumer are shown in Table 4,$5 ;[1,13]$. During the fermentation, the removal of anti-nutritional factors like flatulence increases the nutritional value of fermented cereal products [14]. The fermented foods also have increased keeping quality and reduced cooking time (protecting heat labile vitamins), with comparatively lesser energy input. Not only this, some vitamins in the fermented foods especially vitamin-B group are increased due to synthesis by microorganisms $[15,16]$. These may accumulate in the protoplasm of the microbial cell or released into the food upon cell autolysis, thus improving the quality of food. Astonishingly though it may appear but is a reality that along with fermented foods, we are actually consuming either the microbial cells themselves or their autolytic products, e.g. Roquefort type of cheese or tempeh, where the mold is an integral part of the product and is eaten along with it [17]. The yeasts and bacteria or their byproducts in bread or sausage, sour milk and cheese are consumed along with the products. The yeast employed in fermentation adds flavor to the bread and is eaten along with the bread $[6,18]$.

Table 3: Fermentation as a tool for nutritional improvement.

\begin{tabular}{|r|}
\hline The inclusion of micro-oraganisms along with nutrients in many fermented products enhances their nutritive value. \\
\hline Due to break-down of more complex compounds such as sugars are found which are easily digestible. \\
\hline $\begin{array}{r}\text { Micro-organisms causing fermentations being metabolic too, synthesize several complex vitamins and other growth factors, e.g. riboflavin, vitamin } \mathrm{B}_{12} \\
\text { and the precursor of vitamin } \mathrm{C} .\end{array}$ \\
\hline $\begin{array}{r}\text { By liberation of nutrients locked as indigestible materials in the plant structures and cells, by the enzymes from micro-organisms fermenting the foods } \\
\text { especially the molds. }\end{array}$ \\
\hline $\begin{array}{r}\text { The fermentation can also enhance the nutritional value of plant materials, involving enzymatic splitting of cellulose, hemi cellulose and related } \\
\text { indigestible polymers into simpler digestible componds. }\end{array}$ \\
\hline Fermentaion results in the destruction of anti-nutritional factors improving the nutritive value of fermented foods indirectly.
\end{tabular}


Table 4: Consumption of wine, coronary heart disease and complimentary biological mechanisms.

\begin{tabular}{|c|}
\hline Alcohol \\
\hline Enhances high density lipoproteins by facilitating excretion of cholesterol via liver. \\
\hline Reduces the concentration of the atherogenic apoprotein A-1. \\
\hline Reduces stress. \\
\hline Antioxidants \\
\hline Reduce peroxidation of polyunsaturated fatty acids (PUFA) and low density lipoproteins. \\
\hline Decrease macrophage cell formation. \\
\hline Reduce chronic inflammation tendencies by decreasing peroxide tone. \\
\hline Reduce thrombic tendencies, platelet aggregability to regulate the arachdonic acid cascade. \\
\hline
\end{tabular}

Table 5: Wine antioxidants and their mechanism of action.

Wine and grapes contain a number of antioxidants or potential antioxidants: ascorbic acid, benzoic acid , gallic acid, 2,3 and 2,5. Dihydroxy benzoic acid, epicatechin, quercetin, grape pigment cyanidin.

Absorption of food from the gut, intestinal microflora, ability for metabolism of such foods, gut enzymes, hormones and other intrinsic factors such as age and general health of the individuals.

Phenolics can combine with proteins forming macromolecule making their absorption facile.

Effective scavenging of reactive species

by providing either one hydrogen (salicylic acid, benzoic acid) or a pair of hydrogen or hydride (thiols, hydroquin ones or similar compounds having quinon like structure, FMNH2, FADH2, NAD(P) H2 onto the target substrate serving as one or two electron reductions)

In one electron reduction, hydroxyl radicals are converted into hydroxy compounds

Some of the compounds serve as both electron donor and free radical scavenger depending upon the environment of operation.

Lactic acid bacteria are used to sour milk and which upon consumption to introduce these bacteria in the human intestinal tract. These microorganisms also serve as probiotics which are very important in maintaining the well being of human gut $[1,19]$. These days most of the probiotics are used in the yoghurt fermented milks, ice cream and pharmaceuticals products due to their therapeutic effects [20]. Further, to increase the therapeutic value of the dairy products besides probiotics, prebiotics are also added [21]. Being only slightly more oxidizable than their parent substances, the fermented foods retain much of the energy potential of the starting material [22] therefore, are a source of energy. The proteins in particular are partially hydrolyzed, made more soluble and available nutritionally [1]. Vitamins such as riboflavin, vitamin B12 and the precursor of vitamin-C are increased during fermentation. Many fermented foods have never been investigated at all for their nutritional content especially the therapeutic values. With the availability of highly sophisticated equipment and accurate techniques of analysis extensive evaluation of fermented products should not be a problem.

The therapeutic value of such products calls for in-depth investigations (Details of bioactive compounds generated during the fermentation have been discussed in bioactive compounds). This aspect has been projected several times but critical estimation has never been made in the past. What is generally made is the qualitative estimation of components of wine with therapeutic values and the in depth appraisal could reveal various parameters or markers of the therapeutic values, quantitatively. Similarly for wine consumption several claims of benefits are made like reduction of CVDs, cancer, cure of diabetes but all the studies are reported are from the survey of population rather than from experimental model studies. The positive or negative contribution should come from studies in vivo in human beings to have any significant impacts of the values as a medicine.

\section{Herbal Plant Medicines, Phyto Chemicals and Nutraceutical}

No doubt, allopathic cure is available for most of the disorders but it comes at a price which includes the cost of medicine that is increasing day-by-day and the allopathic medicines are also associated with a variety of side effects. So, herbal or plant medicines are being used from an ancient time all over the world especially India, China and several other countries of Asia [23]. These are also popular but more in rural population and around $80 \%$ of rural population in India depends on it for their primary health care [24]. These plants offer a rich, source of components which provide a variety of health benefits [25]. Such components are known as phyto-chemicals and can act in several ways as those summarized in Table 6. Another group of nutraceuticals include spices which are heterogeneous collections of a wide variety of volatile and non-volatile staple dietary additives. These have a wide variety of natural phyto-chemicals that have complementary as well as overlapping actions [26]. 
Table 6: Action of phyto-chemicals as substrates for various biochemical reactions.

\begin{tabular}{|c|}
\hline Serve as cofactors/ inhibitors of different enzymatic reactions \\
\hline Can act as absorbents/sequestrants that bind to and eliminate undesirable constituents in the intestine \\
\hline Some of these behave like that act as agonists or antagonists of cell surface or intracellular receptor \\
\hline Phyto-chemicals serve as scavengers of highly reactive or toxic chemicals \\
\hline Phyto-chemicals serve as scavengers of highly reactive or toxic chemicals \\
\hline Are selective growth factors for beneficial gastrointestinal bacteria \\
\hline Act as fermentation substrates for useful oral, gastric or intestinal bacteria and selective inhibitors of harmful intestinal bacteria \\
\hline
\end{tabular}

Some of the action of the spices and their constituents are: antioxidant effects, modulation of detoxification enzymes, stimulation of immune system, reduction of inflammation, modulation of steroid metabolism, antibacterial and antiviral effects. These effects are carried out at molecular, cellular, autocrine, paracrine and endocrine mechanisms and possess the role in neuro-modulation, immune-inodulation, anti inflammatory, antioxidant, anti-carcinogenic, anti-mutagenic and psychoactive phenomena. Although Indians are known to consume a large number of spices in their culinary preparation and believe them to have a large medicinal value, the mechanism of their action, target and the concentration etc are not precisely quantified for use as a medicine until recently. The foods containing the phyto-chemicals are termed as nutraceuticals which include various nutrients, dietary supplements, specially designed diets or herbal products of both plant and animal origin which holds great opportunities for food industries to bring out novel food catering to the future needs $[27,28]$. Conceptually, nutraceuticals can be visualized as posiᄀtioned between medicinal drugs and basic nutrition either emphasizing the 'ceutical' (resembling pharma $\neg$ ceuticals or the 'nutri' (towards basic nutrintional concepts). The term 'nutraceuticals' was originally coined in the late 1980s [29]. It has since been used to describe a wide variety of non-pharmaceutical compounds that could have an influence on health and disease states, general well-being and performance [30].

The Table 7 describes the type of nutraceuticals as a source of function while their categories based on the food and their functions are summarized in Table 8. These have a wide range of therapeutic effects against a number of diseases like diabetes, heart disease, common cold, arthritis, cancer, hypertension, dyslipidemia, inflammatory bowel disease, depression etc [25]. Nutraceuticals could be divided into herbal/natural products, dietary supplements and functional foods [25]. These nutraceuticals compounds have antioxidant and other health promoting properties. It is known that the cancer development is a chronic, stepwise complex process culminating into metastasis if not tackled in time. Epidemiological studies now have provided convincing evidence that dietary factors could modify carcinogenesis. A number of phyto-chemicals as well as some plant origin foods with yet un-identified components possess anti-carcinogenic and anti-mutagenic properties as reviewed earlier [25]. Thus, use of these bioactive compounds as chemo-preventive substances, in future, can't be underestimated [31].

Table 7: Categories of nutraceuticals based on source or function.

Those substances with established nutritional value (nutrients e.g. vitamins, minerals, amino acids, fatty acids, polysaccharides etc).

Products of herbs or botanical products in the form of concentrates or extracts (herbals e.g. Aloe vera, wheat grass, ginger, garlic etc).

Compounds derived from other sources serving specific functions such as sports nutrition, weight-loss supplements and meal replacements termed as dietary supplements.

Table 8: The nutraceuticals and their role in disease prevention.

The term nutraceutical is derived from the words 'nutrition' and 'pharmaceutical' thus, nutraceutical is a food or a part of the food which exerts a curative or preventive effect on disease.

The term 'nutraceuticals' was originally coined in the late 1980s It has since been used to describe a wide variety of non-pharmaceutical compounds that may have an impact on health and disease states, general well-being and performance

Foods containing these phytochemicals are known as 'nutraceuticals

However, the term has been used by the consumers, producers and even healthcare profes $\neg$ sionals to refer to many different types of compounds, including (semi-)purified substances from natural sources, plant extracts, dietary supplements, vitamins , minerals etc,

Nutraceuticals include various nutrients, dietary supplements, specially designed diets or herbal products of both plant and animal origin which hold great opportunities for food industries to bring out novel food catering to future needs

These have a wide range of therapeutic effects against a number of diseases like diabetes, heart disease, common cold, arthritis, cancer, hypertension, dyslipidemia, inflammatory bowel disease, depression etc.

Compounds like phenylpropanoids, isoprenoids, polyphenols, anthocynidins, flavonoids, terpenoids, carotenoids, phytoestrogens and alkaloids etc are responsible for the beneficial effects of diet rich in fruits and vegetables.

Melatonin (N-acetyl-5-methoxytryptamine) is also found in plant diets which produce kynuramine, a biogenic amine, by oxidative metabolism.

Kynuramine improves mitochondrial metabolism, acts as cyclooxygenase-2 inhibitor and an important antioxidant 
In brief, there is a high level of interest, and consequently a high consumer demand, for nutraceutical type products by the general public. These types of products are often perceived by the public more favorably than pharma $\urcorner$ ceuticals as these are considered as more 'natural' and less likely to cause any side effects. But, these observations many times are not true [8,32]. At the same time, the nutraceuicals have an added advantage that they are generally easier to obtain, being avail $\neg$ able over the counter in supermarkets, health food shops and pharmacies. All these factors contribute to the consumer interest in the nutraceuticals type of products. The problem is that a particular nutraceutical or phyto-chemical is not even fully investigated and becomes a medicine overnight. It becomes all the more problematic when many a times a phytochemical is commercialized even when it is at the preliminary stage of investigation.

No doubt, the herbal medicine are effective in the cure of such diseases, unfortunately many a times the orthodox approach becomes so strong that even a particular substance is not demonstrated to be effective but it comes in the market for sale. In some cases, this belief grows so much so that many a times the same substance is projected to cure many diseases which cause some sort of re-thinking in the mind of people with rational thinking and analytical mind that how one component could be a cure of all the diseases. So is important to apply modern science to understand the traditional systems of medicine such as the Traditional System of Chinese Medicine (TSCM), Ayurveda which require a multifaceted approach of research for validation. Rather, many of the substances being used are not really investigated in true sense of research following a right approach that these should have been. In many cases, even the active compound is not identified, characterized, what is the effective concentration, acceptable dietary intake or whether these been have proved to be effective or not in the experimental animals also and with what results. So the basics of science behind the use of these nutraceuticals should be systematic investigated in all the aspects of the problem. Not only this, the basic knowledge of science in this area has frequently been misinterpreted or overstretched for commercial purposes [33].

At the same time, it is apparent that interdisciplinary research involving biochemistry, nutrition, microbiology, physiology, pathology and pharmacology should be conducted and is clearly a fertile ground for clinical pharmacology and therapeutics, where such rigorous science is absolutely vital. Irrespective of product type, commercial potential and health benefit area, the functional claims of any nutraceutical product should be evidence-based and need to be sup $\urcorner$ ported by convincing scientific data. Ultimately, the proof of efficacy, as well as of safety, should come from welldesigned and well-executed human studies. It is known that the response of nutraceuticals varies from individual to individual [25] and susceptibility of any Individual's to a particular disease depends on the genetic pre-disposition, environmental factors and lifestyle. Nevertheless, the role of nutraceuticals in prevention, restriction and cure of various diseases is beyond doubt. However, the success will be governed by purity, safety and efficacy of the specific nutraceutical. It however does not exclude that the pharmaceutical and clinical issues which need to be properly tackled and long term clinical research is needed to scientifically validate their role in different diseases. Moreover, it has been observed that herbal medicines show good results when treated as an adjuvant to allopathic medicine, but not as a substitute, in most of the diseases like diabetes, hypertension and cancer etc. which should be kept in mind.

Thus, with a little bit of careful handling, the future of both plant and animal origin nutraceuticals holds exciting opportunities in the medical field. The basic methodology of designing and conducting human studies on the health benefits of nutraceuticals [34] is similar to that of pharmaceutical trials; there are some aspects that need special focus when conducting research on nutraceuticals. For example, since nutraceuticals are often taken as self-medication, the target population, and hence the study of population, may not necessarily be well characterized, as with other studies and population heterogeneity may lead to variabilᄀity in the observed effects. Some allowance for these effects should be kept to make such effective. In the use of nutraceuticals, as such or in combination with allopathic drugs a big concern is the interaction between nutraceuticals in the herbal medicine especially the Traditional System of Chinese Medicine (TSCM) and the synthetic drugs as reviewed earlier [8]. To evaluate critically the evidence regarding interactions between herbal medicinal products (HMPs) and synthetic drugs four electronic databases were searched to identify relevant (Systemic review SRs). While conducting research on nutraceuticals, these aspects should be taken into account. Another concern for the use of nutraceutical is the lack of quality control. Food laws which govern the quality and processing of nutraceuticals lack the specificity required for botanical drugs. Lack of this could lead to adulteration or contamination of nutraceuticals remaining unnoticed and posing a great threat to the health of consumers [35].

It is also important that a distinction is drawn between information obtained from in vitro studies with that of in vivo studies. The mechanism of action along with the efficacy of various Phyto-chemicals in different clinical conditions needs to be established with help of in vivo studies [36]. Many widely used medicinal plants still lack the extensive physiological characterization. Not only this, detailed knowledge about metabolic pathways for biosynthesis of different phyto-chemicals with associated factors and role of genetic makeup and environmental modulations in these biosyntheses is also not yet available and should be undertaken as a part of evaluation of any phyto-chemical or any bioactive compound as a medicine or a part of health food. Finally, the cost of nutraceuticals is another concern which would determine its marketability and ultimately, the consumer acceptance. Rather, it is a major issue. Commercially, available preparations are bound to be purer and more effective forms but much more expensive as compared to the natural ones. So this aspect should be kept in mind while developing a drug or a health food.

\section{Bioactive Substances}

Bioactive substances or compounds are food components which can affect biological processes and thus, influence the body's 
functions or condition and ultimately, health [37]. These compounds considered "bioactive" only if, as a dietary component, they can impart a measurable biological effect at a physiologically realistic level, and, secondly, that the "bioactivity" measured should have the potential (at least) to affect health in a beneficial way, thus excluding from this definition potentially damaging effects such as toxicity, allergenicity and mutagenicity, which are undoubtedly a reflection of "bioactivity" in its broadest sense. Effect and role of bioactive peptides on different biological systems are summarized in Table 9. Numerous sources of bioactivity peptides released from dietary proteins by enzymatic proteolysis, include opiates, antithrombotics, antihypertensive and with properties such as immunomodulating, antilipemic, osteoprotective, antioxidative, antimicrobial, ileum contracting, anticariogenic and growth promoting. Specific peptides can have one or more different biological functions, depending upon their inherent amino acid composition and sequence. The size of active sequences however, may vary from 2 to 20 amino acid residues, and many peptides are known to show multifunctional properties. These peptides improve the functional properties of the foods and can also act as a natural alternative to various synthetic drugs. There is global interest in harnessing bioactive properties of plants and their secondary compounds as alternatives to chemical, drugs and growth promoters.

Table 9: Influence of different biological functions of bioactive peptides

\begin{tabular}{|c|}
\hline Improved uptake of minerals (calcium and iron) (casein-phospho-peptide) \\
\hline ACE-inhibition (casokinin) \\
\hline Gastrointestinal mobility (casomorphin) \\
\hline Antithrombotic agents (casoplatelin) \\
\hline Enzyme secretion and acidification of the stomach \\
\hline Antimicrobial properties (casecidins, lactoferricin) \\
\hline Better utilization of protein \\
\hline Improved appetite and growth \\
\hline
\end{tabular}

A great focus is being presently made on bioactive peptides, as they play very crucial roles in human body as antihypertensive, antioxidant, antimicrobial or immuno modulates, thus have great potential in combating several diseases. Indigenous fermented foods are the major sources of bioactive compounds, reflecting the great usefulness of these foods in human health. More research in this direction is the need of the hour. Similarly, their use in medicine is an equally excited field of future research. The different bioactives within a particular nutraceutical or within a diet could exert (unknown) antagonistic, agonistic or synergistic effects which could possibly complicates the interpretation of any research find -ings [30]. Besides, other interactive effects may also arise when nutraceutical approaches are placed in a broader lifestyle context, a concept that is generating a great interest these days. In the past few years, rigorous regulatory assess $\neg$ ments for the approval of health claims, such as carried out by the EFSA (European Food Safety Authority) under the European Union health claims legislation (European Union. Regulation (EC) No 1924/2006 [38], have been implemented. Such types of regulatory measures need to be taken up both at the legislation and the implementing agencies level in other countries also. This holds good for the other types of nutraceuticals or phyto- chemicals when used as medicine or in health food.

\section{Application of Metabolimics and other Analytical Tools}

Metabolomics is recognized as a powerful top-down system biological approach to understand the genetic-environmenthealth paradigms paving new avenues to identify clinically relevant biomarkers as has been described earlier [39-41]. It is nowadays commonly used in clinical applications shedding new light on physiological regulatory processes of complex mammalian systems with regard to disease aetiology, diagnostic stratification and, potential, mechanism of action of therapeutic solutions. A key feature of metabolomics lies in its ability to underpin the complex metabolic interactions of the host with its commensal microbial partners providing a new way to define individual and population phenotypes [42]. The metabolome is the complete set of small molnecule metabolites (such as metabolic intermediates, hor $\neg$ mones and other signalling molecules and secondary metabolites) which are within a biological sample.

Mainly it is based on the quantitative measurement of dynamic metabolic changes of living systems in response to genetic modifications or physi $\neg$ ological stimuli, including nutrients and drugs [43]. By the global study of low molecular weight metabolites ( $<1500 \mathrm{Da}$ ) in bio-fluids (plasma/serum and urine) [44] and tissues [41] metabolomics assures the characterization of an individual metabolic phenotype. Metabolomics gives new insights the complex metabolic networks of mammalian organisms. It has several clinical applications like gastrointestinal disease, metabolic syndrome and related cardio-metabolic disorders, clinical applications for cancer diagnosis, clinical applications for neurological and psychiatric disorders [42]. Recently, traditional Chinese herbal medicine (TCHM) has increasingly attracted the attention of both patients and medical community. However, owing to the multicomponent systems with massive unknown components and misunderstanding, complication theories of TCHMs, there is left a great challenge in their analyses and quality control, thus, has severely restricting the wide spread application of TCHMs. 
Traditional biotechnology has been utilized by human civilization for long in wide aspects of our daily life, such as wine and vinegar production, which can generate new phyto-chemicals from natural products using micro-organism (Fermented foods have been discussed earlier). With advanced biotechnology, diverse applications and advantages could be exhibited not only in bringing benefits to increase the diversity and composition of herbal phytochemicals, but also helping to elucidate the treatment mechanism and accelerate new drug discovery from Chinese herbal medicine (CHM) Wong 2016. Accordingly, applications on Phyto-chemical biotechnologies and microbial biotechnologies have been promoted to enhance Phyto-chemical diversity. These include cell labelling and imaging technology and-omics technology which have been utilized to elucidate CHM treatment mechanism.

Their application in the Traditional Chinese Herbal Medicines (TCHMs) is promising approach for the treatment of various diseases which have attracted increasing attention all over the world. Chemo-metrics is one of the useful tools in the quality control of TCHMs harnessing mathematics, statistics and other methods to acquire information maximally from the data obtained from various analytical approaches [19] To achieve the comprehensive quality control of Chinese herbal medicine (CHM), the conventional practice of selecting a single marker for testing has gradually been replaced by the determination of multiple active components based on the characteristics of the synergistic interaction of CHM and applicability of sophisticated analytical techniques [34]. Furthermore, quantitative analysis of multicomponents by single marker (QAMS) was proposed and accepted as a new method to reflect the internal quality of CHM. The advent of nutrigenomic sciences with stress on metabolomics opens new research vistas for biomarker discovery. Based on a concept of a metabolic pattern or signature a large variety of such biomarkers are increasingly being proposed for various diseases. With the advancement of analytical techniques can enable new diagnostic assays with improved sensitivity and specificity over the current/ conventional biomarkers to be implemented in routine laboratories. Yet, despite these potentials, direct translation of metabolomics findings to prognostics screening and personalized diagnostic medicine is still at an early stage especially, the large unfamiliarity of the clinical community with the field of metabolomics.

\section{References}

1. Joshi V, Pandey A (1999) Biotechnology: Food fermentation. In Biotechnology: Food Fermentation, Joshi VK and Pandey A (Eds.), Educational Publishers and Distributors, New Delhi, India.

2. Joshi VK (2011) Handbook of Enology: Principles, Practices and Recent Innovations. 3 Volumes set Asia-Tech Publisher and Distributors, New Delhi, India.

3. Sharma S, Joshi VK, Thakur NS (2011) Lactic acid fermented foods. In: Food Biotechnology: Principles and Practices. Joshi VK, Singh RS (Eds.), IK International Publishing House, New Delhi, India.

4. Halliwell B (2013) The antioxidant paradox, less paradoxical now? Br J Clin Pharmacol 75(3): 637-644.

5. Arrmoto K (1961) Nutritional research on fermented soyabean products.
In : Meeting the protein needs of infants and pre-school children. Publ. 843. Natl Acad Sci-Natl Res Countil, Washington, USA.

6. Joshi VK, Siby John (2002) Antimicrobial activity of apple wine against some pathogenic and microbes of public health significance. Alimentaria $67-72$

7. Joshi VK, Bhutani VP, Thakur NK (1999) Composition and nutrition of fermented products. In : biotechnology: food fermentation Vol I, Joshi VK, Ashok Pandey (Eds.) Vol. I 259-320 Educational Publishers and Distributors, New Delhi, India.

8. Prakash D, Gupta C (2011) Role of phytoestrogens as nutraceuticals in human health-A review. Biotechnology: An Indian J 5: 1-8.

9. Joshi VK (2015) Indigenous fermented foods of south asia. Rob Nout and Prabir Sarkar, Series (Eds.), The Fermented Foods and Beverages Series, CRC Press, Florida, USA.

10. Joshi VK (2011) Handbook of Enology: Principles, Practices and Recent Innovations. 3 Volumes set Asia-Tech Publisher and Distributors, New Delhi, India.

11. Kalra EK (2003) Nutraceutical-definition and introduction. AAPS Pharm Sci 5(3): 27-28.

12. Neale C, Camfield D, Reay J, Stough C, Scholey A (2013) Cognitive effects of two nutraceuticals Ginseng and Bacopa benchmarked against modafinil: a review and comparison of effect sizes. Br J Clin Pharmacol 75(3): 728-737.

13. Joshi VK, Lakhanpal, Pooja, Vikas K (2013) Occurrence of Patulin, its dietary intake through consumption of apple and apple products and methods of its removal. International Journal of Food and Fermentation Technology 3(1): 1-14.

14. Joshi VK (2012) Health benefits and therapeutic value of fermented foods. In Health Foods:Concept, Technology and Scope. Gupta RK, Bansal S, Mangal M (Eds.), Biotech, New Delhi, India.

15. Joshi VK, Pandey A (1999) Biotechnology: Food Fermentation : (Microbiology, Biochemistry and Technology). Educational Publisher \& Distributors, Ernakulum, New Delhi, India.

16. Sharma R (2018) Health Foods and Nutraceuticals from Fruit and Vegetables. In : Advances in Fruit and vegetable Processing. New India Publishing Agency, India.

17. Posadzki P, Watson L, Ernst E (2013) Herb-drug interactions: an overview of systematic reviews. Br J Clin Pharmacol 75(3): 603-618.

18. Joshi VK, Sandhu DK, Thakur NS (1999) Fruit based alcoholic beverages In : Biotechnology : Food Fermentation, Vol. II. Joshi VK, Ashok Pandey (eds.), Educational Publishers and Distributors, New Delhi, India.

19. Huang, Zhenwei Su, Rihui Ruan (2016) Current application of chemometrics in traditional Chinese herbal medicine research. J Chromatogr B Analyt Technol Biomed Life Sci 1026: 27-35.

20. Mingrone G, Castagneto GL, Mace K (2013) Use of di-carboxylic acids in type 2 diabetes. Br J Clin Pharmacol 75(3): 671-676.

21. Hord NG (2008) Eukaryotic microbiotic crosstalk: potential mechanisms for prebiotics and probiotics. Annu Rev Nutr 28: 215-231.

22. Mingrone G, Lidia CG, Katherine M (2013) Use of dicarboxylicacids in type 2 diabetes, Br J Clin Pharmacol 75(3): 671-676.

23. Iriti M, Faoro F (2006) Grape phytochemicals: A bouquet of old and new nutraceuticals for human health. Med Hypotheses 67(4): 833-838.

24. Joshi VK, Bhutani VP, Thakur NS (2005) Composition and nutrition of fermented products. In: Joshi VK, Pandey Ashok (Eds.), Biotechnology: Food fermentation microbiology, biochemistry and technology 1 EPD, New Delhi, India.

25. Das L, Bhaumik E, Raychaudhuri U, Chakraborty R (2012) Role of nutraceuticals in human health. J Food Sci Technol 49(2): 173-183. 
26. Lidder S, Webb AJ (2013) Vascular effects of dietary nitrate (as found in green leafy vegetables and beetroot) via the nitrate-nitrite-nitric oxide pathway. Br J Clin Pharmacol 75(3): 677-696.

27. Kennedy NP, Tipton KF (1990) Ethanol metabolism and alcoholic liver disease. Essays Biochem 25: 137-195.

28. Patil CS (2011) Current trends and future prospective of nutraceuticals in health promotion. Bio Info Phramaceutical Biotechnology 1(1): 1-7.

29. Dillard CJ, German JB (2000) Phytochemicals: nutraceuticals and human health. J Sci Food Agric 80: 1744-1756.

30. Cherdshewasart W, Sutjit W, Pulcharoen K, Chulasiri M (2009) The mutagenic and antimutagenic effects of the traditional phytoestrogenrich herbs, Puerariamirifica and Puerarialobata. Braz J Med Biol Res 42(9): 816-823.

31. Wong VK, Yuen K, Law BY, Yao XJ (2016) Advanced research technology for discovery of new effective compounds from Chinese herbal medicine and their molecular targets. Pharmacol Res 546-555.

32. Senapathi AK, Anila kumari, Dev Raj, Prajapati JP, Sandhu KS, et al. (2016) Traditional Fermented Foods-Composition and Nutritive Value. In:Indigenous Fermented foods of South Asia, Joshi VK, (Edn.), CRC Press, Taylor and Francis, Boca Raton, Florida USA.

33. Zhu Chunsheng, Xiaoping Li, Bing Zhang, Zhijian Lin (2017) Quantitative analysis of multi-components by single marker-a rational method for the internal quality of Chinese herbal medicine. Integr Med Res 6(1): 1-11.

34. Pederson CS (1971) Microbiology of Food Fermentation. AVI Pub Co Inc. Westport, Connecticut, USA.

35. Durmic Z, Blache D (2012) Bioactive plants and plant products: Effects on animal function, health and welfare, Animal Feed Science and Technology 176: 150-162.
36. Aditi Sourabh, Amit KR, Arjun Chauhan, Kumarswami Jeyaram, Malai Taweechotipatr, et al. (2016) Health-Related Issues and Indigenous Fermented Products. In: Indigenous Fermented foods of South Asia, Joshi VK, (Edn.), CRC Press, Taylor and Francis, Boca Raton, Florida, USA.

37. Moller NP, Scholz-Ahrens KE, Roos (2008) b Bioactive peptides and proteins from foods: Indication for health effects. Eur J Nutr 47(4): 171182.

38. European Union (2006) Regulation (EC) No 1924/2006 of the European Parliament and of the Council of 20 December 2006 on nutrition and health claims made on foods. Official Journal of the European Union.

39. Renaud S, Delorgeril M (1992) Wine, Alcohol, Platelets and the French Paradoxfor coronary heart disease, Lancet 339(8808): 1523-1526.

40. Beckonert O, Keun HC, Ebbels TM, Bundy J, Holmes E, et al. (2007) Metabolic profiling, metabolomic and metabonomic procedures for NMR spectroscopy of urine, plasma, serum and tissue extracts. Nat Protoc 2(11): 2692-2703.

41. Collino S, Martin FP, Rezzi S (2013) Clinical metabolomics paves the way towards future healthcare strategies. Br J Clin Pharmacol 75(3): 619629.

42. Nicholson JK, Lindon JC (2008) Systems biology: metabonomics. Nature 455(7216): 1054-1056.

43. Nicholson JK, Foxall PJ, Spraul M, Farrant RD, Lindon JC (1995) 750 MHZ ${ }^{1} \mathrm{H}$ and ${ }^{1} \mathrm{H}-{ }^{13} \mathrm{C}$ NMR spectroscopy of human blood plasma. Anal Chem 67(5): 793-811.

44. Nicholson JK, Wilson ID (1989) High resolution proton magnetic resonance spectroscopy of biological fluids. Prog Nucl Magn Reson Spectrosc 21(5): 449-501.
Creative Commons Attribution 4.0

International License

For possible submissions Click Here

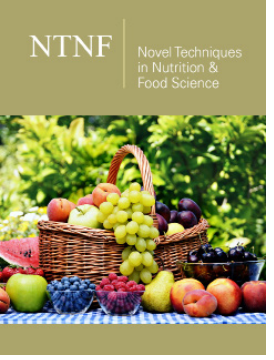

Novel Techniques in Nutrition and Food Science

\section{Benefits of Publishing with us}

- High-level peer review and editorial services

- Freely accessible online immediately upon publication

- Authors retain the copyright to their work

- Licensing it under a Creative Commons license

- Visibility through different online platforms 